\title{
Sesongjusterte fødselsfrekvenser er Poisson-fordelte
}

\begin{abstract}
BAKGRUNN Variasjon i fødselsfrekvenser har betydning for aktivitetsplanlegging på fødeavdelinger. I tidligere studier av fenomenet har vanligvis elektive fødsler vært inkludert $i$ beregningene. I en dansk studie av spontane fødsler fant man at fødselsfrekvenser var godt modellert av en Poisson-prosess. Noe uventet var det også ukesvariasjon i spontane fødsler. At fødselsfrekvenser er Benford-fordelte, ble hevdet i en annen studie. Formålet vårt var å etterprøve disse resultatene.
\end{abstract}

MATERIALE OG METODE Vi analyserte 50017 spontane fødsler ved Akershus universitetssykehus i perioden 1999-2014. For å undersøke Poisson-fordeling av fødslene plottet vi varians over glidende gjennomsnitt. Vi spesifiserte ulike Poisson-regresjonsmodeller med antall fødsler på en gitt dag som utfallsvariabel. Forklaringsvariablene var ulike kombinasjoner av år, måned, ukedag og datoens tverrsum.

RESULTATER Relasjonen mellom varians og gjennomsnitt passer med en underliggende Poisson-prosess. Benford-fordeling ble avkreftet med en «goodness-of-fit»-test $(p<0,01)$. Grunnmodellen med forklaringsvariablene år og måned bedres signifikant $(p<0,001)$ ved å legge til ukedag som forklaringsvariabel. Det fødes 7,5\% flere barn på tirsdager enn på søndager. Forklaringsvariabelen datoens tverrsum er ikke-signifikant $(p=0,23)$ og øker heller ikke forklart varians.

FORTOLKNING Spontane fødsler er godt modellert med en tidsavhengig Poisson-prosess når måneds- og ukedagsvariasjon inkluderes. Sommeren har høyest frekvens mot juni og juli, fredag og tirsdag utpeker seg som travle dager, og det er minst aktivitet i helgen.

Å kunne estimere forventet antall ikke-elektive fødsler på en gitt dag, og dermed hvordan aktiviteten på fødeavdelinger vil variere gjennom uken og året, er av stor nytte for fødeklinikkledere og andre beslutningstakere i helsevesenet. Det gjør det lettere å legge en optimal bemannings- og ressursstrategi på den lokale fødeavdelingen, men også å forstå hvordan størrelsen på fødeavdelingen henger sammen med forventet variasjon. En fødeavdeling har lav andel elektiv virksomhet kombinert med relativt akutte behov hos pasientene, og kvaliteten på tjenesten kan derfor være sårbar for store svingninger i pasienttilstrømningen. En god modell for fødselsfordelingen er nyttig for å kunne predikere fødselstopper og for å kvantifisere den resterende usikkerheten slik at en adekvat reservekapasitet kan bygges opp.

Det er publisert flere studier om fordelingen av fødsler, sesongvariasjoner er godt beskrevet, og flere finner overhyppighet av fødsler på mandager og underhyppighet $\mathrm{i}$ helger og på offentlige helligdager $(1-10)$. De fleste av disse studiene er imidlertid eldre og har ikke korrigert for elektive fødsler, dvs. elektive keisersnitt og induserte fødsler. Siden elektive fødsler i noen grad planlegges, vil inklusjon av disse forstyrre den naturlige variasjonen i fødselsrater. De representerer også et mindre problem for planleggingen av fødselsomsorgen, nettopp fordi de kan flyttes til et annet tidspunkt dersom det passer bedre.
Etter det vi kjenner til, er det bare én nyere dansk studie som har skilt ut elektive fødsler (9). Her finner man at fødsler er Poissonfordelte (11), med sesongvariasjon og - noe uventet - at det fortsatt er en betydelig ukedagsvariasjon med færre fødsler i helgene. I en artikkel $i$ et ikke-fagfellevurdert tidsskrift (12) som ble omtalt i Tidsskriftet (13), hevdes det at dagens datotalls tverrsum (ramme 1) er en forklaringsvariabel for forventet antall fødsler på en gitt dag. Mer spesifikt er hypotesen at lavere tverrsum gir økt forventet antall fødsler $(12,13)$. Videre påstås det at fordelingen til fødslenes tverrsummer (en fødsels tverrsum er definert som tverrsummen til datotallet til dagen fødselen fant sted) er såkalt Benford-fordelte (14).

I denne studien har vi etterprovd disse resultatene med data over ikke-elektive fødsler fra Akershus universitetssykehus i Lørenskog. Målet var å undersøke følgende hypoteser:

- Fødsler er Poisson-fordelte og det er en systematisk ukes- og månedsvariasjon

- Fødsler er Benford-fordelte over datotall eller fødsler hoper seg opp på dager med datotall med lav tverrsum

\section{Materiale og metode \\ Teori}

Tidspunktet for en fødsel er gitt av unnfangelsestidspunktet og svangerskapets lengde. Vi antar at en god modell for antall unnfan-

\author{
Mathias Barra \\ Jonas C. Lindstrøm \\ Helsetjenesteforskning \\ Akershus universitetssykehus \\ Samantha S. Adams \\ Allmennlegevakten \\ Legevakten i Oslo

\section{Liv A. Augestad} \\ l.a.augestad@medisin.uio.no \\ Avdeling for helseledelse og helseøkonomi \\ Universitetet i Oslo \\ og \\ Helsetjenesteforskning \\ Akershus universitetssykehus
}

ब1

Engelsk oversettelse på www.tidsskriftet.no

\section{HOVEDBUDSKAP}

Spontant igangsatte fødsler er godt modellert med en tidsavhengig Poisson-prosess når måneds- og ukedagsvariasjon inkluderes

Det er høyest frekvens av fødsler i månedene juni og juli, og fredager og tirsdager utpeker seg som de travleste ukedagene

Det er lavest frekvens av fødsler i helgen 
gelser er en (tidsavhengig) Poisson-prosess, fordi unnfangelsene er uavhengige hendelser. Matematisk betyr dette at forventet ventetid til neste unnfangelse er negativt eksponentialfordelt:

- forventet ventetid til neste unnfangelse er $\lambda^{-1}(\beta)$

- med varians $\lambda^{-2}(\beta)$,

$\operatorname{der} \beta=\beta_{1}, \ldots, \beta_{\mathrm{k}}$ er parametere som kan variere med tiden, for eksempel sesong. Den resulterende Poisson-prosessen har forventet antall unnfangelser per tidsenhet lik $\lambda(\beta)$ med samme varians $\lambda(\beta)$. Om det ovenstående er en god tilnærming til unnfangelsesprosessen på befolkningsnivå, så følger det at også fødsler er en tilnærmet Poissonprosess, med noe ekstra varians som skriver seg fra den variable lengden på svangerskapene. Siden parametere kan variere med tiden, utelukker ikke en underliggende Poisson-fordeling av fødsler at det i tillegg kan være noe systematisk variasjon som kan tilskrives faktorer i perioden rundt termin, blant annet forklaringsvariabler knyttet til ukedager eller datotall. I tillegg vil utviklingen mot flere elektive forløsninger kunne påvirke hvor god denne modellen er, f.eks. har keisersnittandelen i Norge økt fra 1,8\% i 1967 til 16,9\% i 2013 (15).

Data

Tallmaterialet i denne studien er datoene for alle fødsler ved Akershus universitetssykehus i perioden 1.1.1999-31.12.2014 $(\mathrm{N}=65528)$. Førsteforfatter hadde tilgang til disse dataene som medarbeider på et internt analyseprosjekt for Kvinneklinikken, som er godkjent av personvernombudet. Dataene besto av én enkelt tabell der det for hver dato i det aktuelle tidsrommet fremkom antallet fødsler med spontan fødselsstart som var registrert den datoen. Flerlingfødsler teller her som én fødsel per barn. I et stort datasett vil elektive fødsler eksempelvis kunne føre til en lavere frekvens av fødsler på den 1 . i måneden i Norge. Dette skyldes at man i løpet av ett år har to faste fridager som faller på den 1 . i måneden (1. januar og 1. mai), der færre fødsler induseres og færre keisersnitt planlegges.

En del fødsler som starter spontant ender opp med akutt keisersnitt. Disse fødslene er talt opp i dataene som hovedanalysene er gjort på. Alle analysene er også repetert på et redusert datasett der spontane fødsler som endte med akutt keisersnitt er utelatt når hver datos fødsler er talt opp.

Dataene som ble benyttet $\mathrm{i}$ analysene er anonymisert og inneholder ikke personidentifiserbar informasjon.

\section{Analyser}

Alle statistiske analyser er utført i statistikkverktøyet $\mathrm{R}(16,17)$. Vi plottet et glidende gjennomsnitt (over henholdsvis 90, 360 og 720 forutgående dager) for antall ikke-elektive fødsler, mot samme periodes varians, for perioden 1.1. 2001-31.12. 2014.

Vi plottet også de relative frekvensene av fødslenes tverrsummer mot Benford-fordelingen og utførte khikvadrattilpasningstest ( $\chi^{2}$ goodness-of-fit) (17) på de observerte frekvensene. I en slik test er nullhypotesen at dataene $e r$ Benford-fordelte slik at man vil forkaste denne hypotesen med høyere sannsynlighet dess lavere $p$-verdier man observerer. Frekvensene av fødslenes tverrsummer ble beregnet over fødslene med datotall $1-27$. Dette er begrunnet $i$ at man ellers vil se en overopphopning på 1-4, siden disse tverrsummene forekommer med høyere frekvens enn de resterende (datoene 28., 29., 30. og 31. gir én ekstra dag med tverrsummene 1-4 i de månedene som har dem).

Vi spesifiserte ulike Poisson-regresjonsmodeller, alle med utfallsvariabel $N o B$ (antall fødsler på en gitt dag). I en Poisson-regresjonsmodell antar vi at utfallsvariabelen følger

\section{RAMME 1}

\section{Tverrsum}

Datotallet til en dag er rett og slett ordenstallet i datoen: fredag 13. mars 2015 har for eksempel datotall lik 13. Tverrsummen til et tall skrevet i det sedvanlige titallssystemet er definert som summen av sifrene som inngår i tallet. Videre repeterer vi denne operasjonen til vi ender med et tall mellom 1 og 9 . For eksempel er tverrsummen til 21 lik $2+1=3$, mens tverrsummen til 29 finner vi ved $2+9=11$ og deretter $1+1=2$, slik at tverrsummen til 29 er lik 2

en Poisson-fordeling, i motsetning til ordinære regresjonsmodeller der man antar en normalfordeling. Poisson-fordelingen er den vanligste fordelingen å bruke for å modellere variabler som er definert over ikke-negative
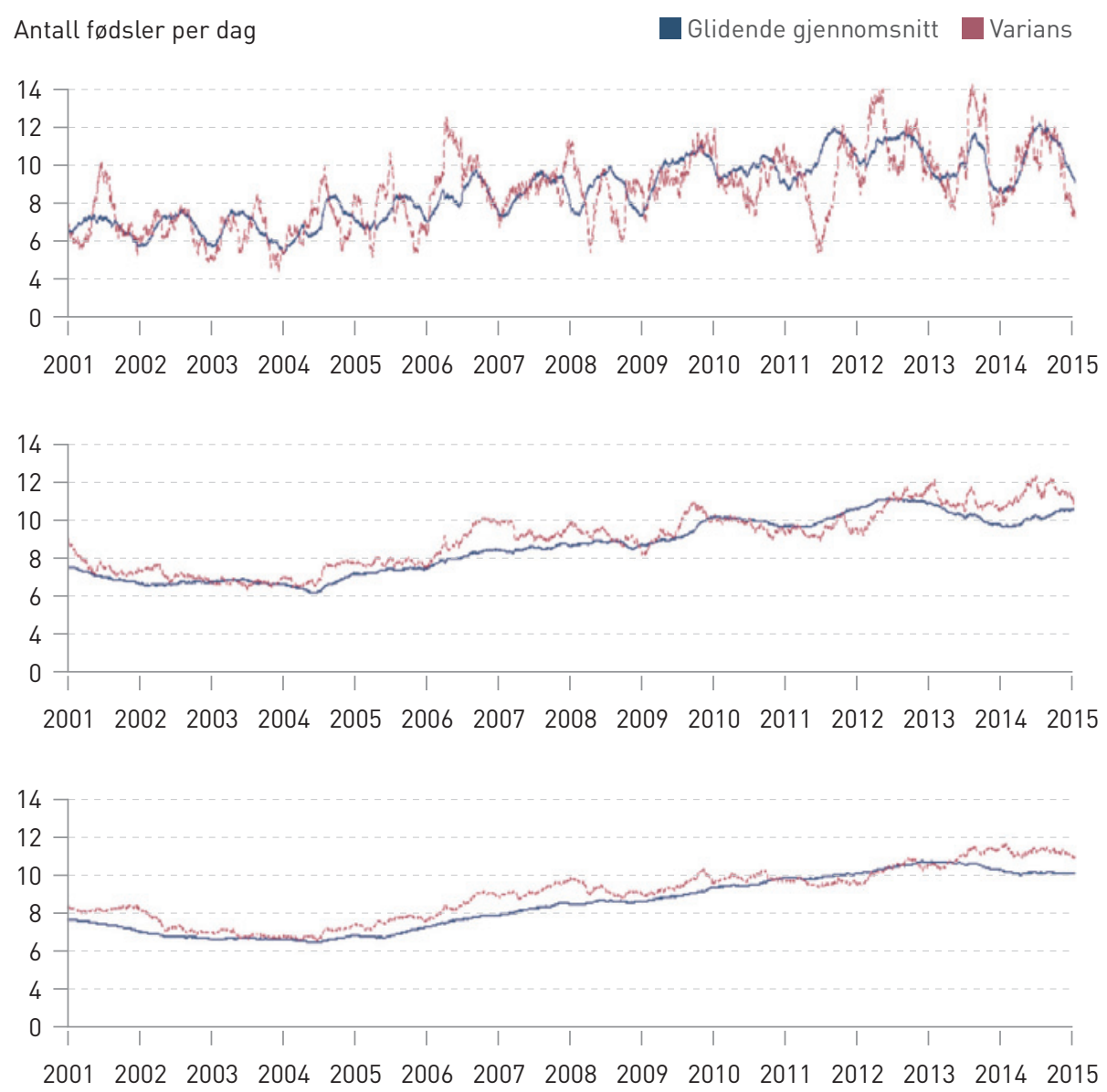

Figur 1 Glidende gjennomsnitt og varians. Øverste panel viser glidende gjennomsnitt/varians beregnet over de siste 90 dagen, det midterste over de siste 360 dagene, det nederste over de siste 720 dagene. For best å kunne se panelene i sammenheng er plottene beregnet for 2001-13. Et gitt punkt på den øverste grafen viser gjennomsnittlig antall fødsler (blå/heltrukket kurve) over de forutgående 90 dagene, $i$ de to nederste representerer punktet gjennomsnittet over henholdsvis de foregående 360 og 720 dagene. Det samme gjelder for variansen (rød/stiplet kurve) 


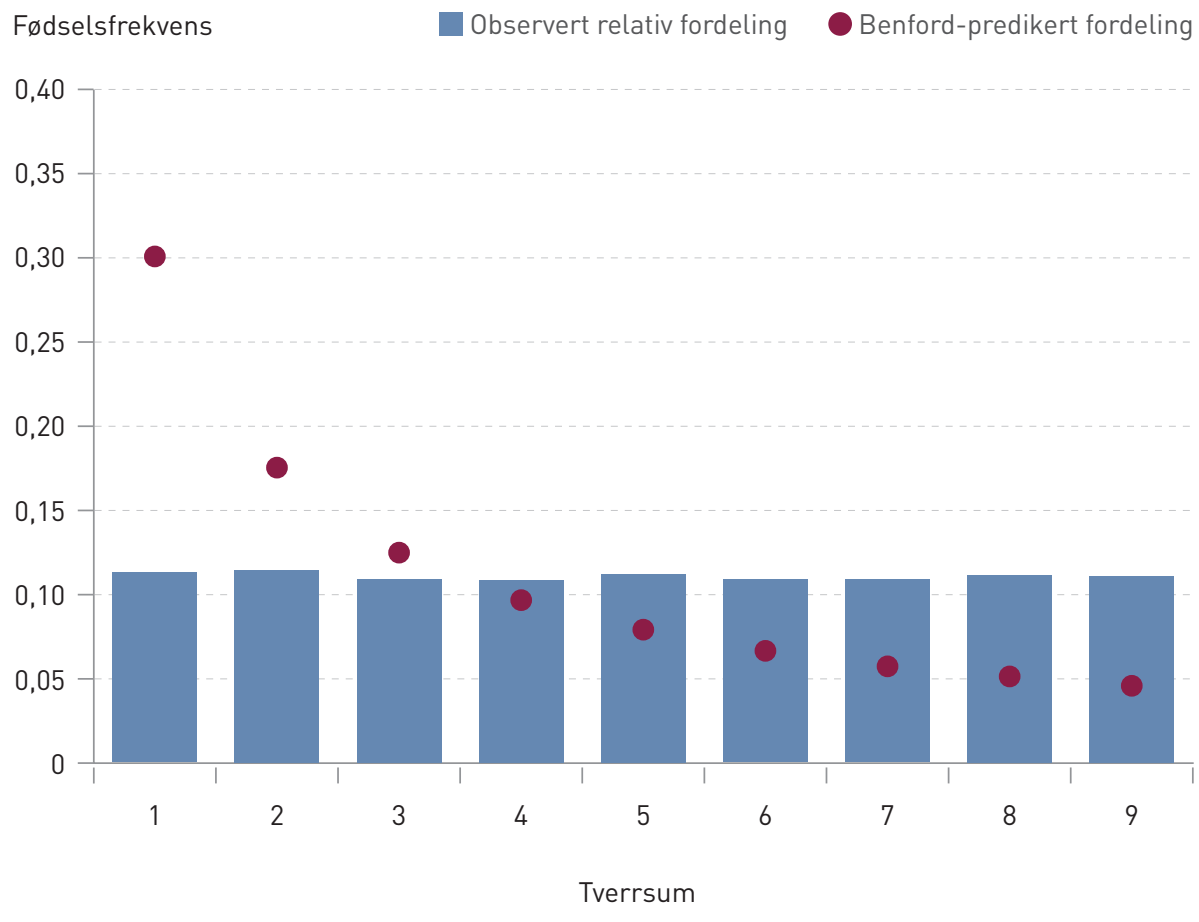

Figur 2 Benford-predikert fordeling versus observert fordeling. Den Benford-predikerte fordelingen på de ulike tverrsummene er markert med prikker, mens den observerte fordelingen er markert med stolper heltall, noe som typisk kjennetegner situasjoner der man teller antall hendelser i løpet av et tidsrom. Forklaringsvariablene var ulike kombinasjoner av år, måned og ukedag (UKD) (1999, januar og søndag er referansekategorier for disse forklaringsvariablene) samt variabelen datotalls $(1-31)$ tverrsum (TVS). Vi vurderte modellene opp mot hverandre med standard modellseleksjonsmetoder: Akaikes informasjonskriterier (Akaike information criterion, AIC) (18), determinasjonskoeffisienten $\mathrm{R}^{2}$ (19) og sannsynlighetsratio (likelihood ratio).

Eventuell signifikant ukedags- eller tverrsumvariasjon avdekket av regresjonsanalysen ble beskrevet som forventet prosentvis økning på aktuelle ukedager/datotall.

\section{Resultater}

Til sammen 50017 fødsler med spontan start ble analysert. Av disse ble de 46748 som ikke endte $i$ et akutt keisersnitt analysert $i$ en separat analyse i tillegg. Tallene som presenteres under er fra analysen av de 50 017. Tallene er tilnærmet like i begge tilfeller. Dette betyr at ingen av de variablene vi analyserer - ukedag, sesong, år eller tverrsum - påvirker sannsynligheten for at en spontant igangsatt fødsel ender $i$ et akutt keisersnitt.

\section{Plott over glidende gjennomsnitt}

Kurvene for glidende gjennomsnitt og varians over henholdsvis de siste 90, 360 og 720 dager er fremstilt i figur 1 . Vi ser en
Tabell 1 Modellseleksjonskriterier for modeller der man har inkludert de to resterende forklaringsvariablene, ukedag og tverrsum, som potensielt kan beskrive andre tidsavhengigheter. Vi vurderte modellene opp mot hverandre med standard modellseleksjonsmetoder: Akaikes informasjonskriterier (AIC), determinasjonskoeffisienten $\mathrm{R}^{2}$ og sannsynlighetsratiotest

\begin{tabular}{lllll} 
Modell & AIC & $R^{2}$ & P-verdi & (Komparator) \\
Grunnmodell $(G)^{2}$ & 29017,0 & 0,225 & - & - \\
G + Ukedag & 29002,5 & 0,229 & $<0,001$ & (G) \\
G + Tverrsum & 29017,5 & 0,225 & $=0,229$ & (G) \\
G + Ukedag + Tverrsum & 29003,1 & 0,229 & $=0,231$ & (G+UKD) \\
& & & $<0,001$ & (G+TVS) \\
\hline
\end{tabular}

${ }^{1}$ P-verdi for sannsynlighetsratiotest med komparatormodell angitt i parentes til høyre for p-verdien. Lav p-verdi betyr signifikant bedre tilpasning

${ }^{2}$ Modell med forklaringsvariabler for år og måned tydelig sesongvariasjon i figuren med 90dagers gjennomsnitt. For en Poisson-prosess forventer vi at variansen vil følge gjennomsnittet. Resultatet i figur 1 ser i stor grad ut til å stemme overens med en underliggende Poisson-prosess: Variansen avviker ikke veldig mye fra gjennomsnittet, den varierer rundt gjennomsnittet og variansen er likere gjennomsnittet når det er beregnet over lengre tidsperioder. Videre ser vi at gjennomsnittlig antall ikke-elektive fødsler per dag er økende fra 2005, men med en nedgang fra medio 2012 som tar seg opp igjen mot slutten av 2014 .

\section{Tverrsummenes fordeling}

Et plott over fordelingen til tverrsummene til de 44470 fødslene med datotall $1-27$ er vist mot Benford-fordeling i figur 2 og viser et sterkt avvik. Benfords tilpasningstest $(\mathrm{p}=0,007425)$ avkrefter hypotesen om Benford-fordeling av fødslenes tverrsummer.

\section{Regresjonsanalyse - modellvalg}

Regresjonsanalysene viste at år og måned var viktige forklaringsvariabler. Tabell 1 viser seleksjonskriterier for modeller der man har inkludert de to resterende forklaringsvariablene, ukedag $U K D$ og tverrsum TVS, som potensielt kan beskrive andre tidsavhengigheter.

Alle Poisson-regresjonsmodeller der ikke både år og måned var inkludert, passet dårlig til observasjonene. Dette ble indikert både av sannsynlighetsratiotester mot en modell uten noen forklaringsvariabler $(p<0,001)$ og Akaikes informasjonskriterier (ikke vist). Det motsatte holdt for alle modeller der år og måned var inkludert (tilpasningstest, $\mathrm{p}>0,100)$. AIC-skåren var lavere i modeller som inkluderte tverrsumvariabelen og ukedagsvariabelen enn i modellene der disse ikke var med. Determinasjonskoeffisienten $\mathrm{R}^{2}$ indikerer at tverrsumvariabelen ikke øker modellens forklaringsevne, noe ukedagsvariabelen gjør. Trinnvis khikvadrattesting av modeller med ukedags- og tverrsumvariabler viser at modellen med ukedagsvariabel passer signifikant bedre enn modellen med tverrsumvariabel, og at tverrsumvariabelen ikke bidrar med noen prediksjonsverdi. En sannsynlighetsratiotest på om modellen blir bedre av å inkludere tverrsum i tillegg til ukedag er ikke signifikant.

Modellen som utpekte seg som best, inkluderte forklaringsvariablene år, måned og ukedag.

\section{Regresjonsanalyse - beste modell}

Årsvariasjonen er allerede beskrevet over. Månedsvariasjonen viser en topp i sommermånedene og en bunn fra oktober til januar. Ukedagsvariasjonen var sterk og signifi- 
kant, med markante topper fredag og tirsdag som kontrast mot et lavere forventet antall spontane fødsler onsdag-torsdag og enda lavere forventet antall fødsler lørdag-søndag (tab 2).

Alle analysene der fødsler som endte med et akutt keisersnitt ble utelatt, viste de samme resultatene, med tilnærmet like koeffisienter, tilpasningsparametere og p-verdier.

\section{Diskusjon}

Denne studien viser at spontant igangsatte fødsler er godt modellert med en tidsavhengig Poisson-prosess når måneds- og ukedagsvariasjon inkluderes. Måneds- og ukedagsvariasjon har høy prediksjonsverdi: Det er høyest frekvens av fødsler i månedene juni og juli, og fredager og tirsdager utpeker seg som de travleste ukedagene. Det er lavest frekvens av fødsler i helgen. Videre fant vi at tverrsummen til fødslenes datotall ikke er Benford-fordelte. Det er ingen opphopning av fødsler på dager med datotall med lav tverrsum. Tverrsummen tilfører ingen forklaringskraft og kan utelates fra modeller over fødsler.

Én mulig feilkilde her er praksisen der man i perioder med mange forventede fødsler sender kvinner til andre sykehus i nærheten med forventet ledig kapasitet. Dette kan føre til at man observerer en noe lavere varians enn det en Poisson-modell vil predikere, fordi det kan bli færre dager med veldig mange fødsler enn modellen skulle tilsi.

Det er ingen grunn til å forkaste hypotesen om at en Poisson-prosess er en god matematisk modell for forventet antall ikkeelektive fødsler. Hypotesen om at datotallets tverrsum har effekt på fødselsrater $(12,13)$, ved Benford-fordeling eller på annet vis, kan forkastes. Tilpasningstestene (goodness-offit) med tanke på Poisson-fordeling gir sterk støtte til Gam og medarbeideres resultater (9), og funnene våre bekrefter det generelle mønsteret for sesongvariasjon beskrevet av Aarnes \& Andersen (10)

Dette kan ha implikasjoner for beslutningstakere i helsevesenet. For planlegging av driften ved fødestuer kan det være stordriftsfordeler å hente med tanke på variasjonen i antall fødsler fra dag til dag. Dersom man legger til grunn en Poisson-fordelt ankomst av nye fødende, vil standardavviket øke med kvadratroten av forventet antall fødsler. Dette betyr at dersom man planlegger med en del overkapasitet for å møte toppene, vil disse være relativt mindre i én stor avdeling enn $i$ to mindre. For eksempel vil en avdeling med forventet daglig antall fødsler lik 8 forutsette at antall fødsler overstiger 15 kun $1 \%$ av dagene. Tilsvarende vil en avdeling med forventet antall daglige fødsler lik 10 forvente at antallet fødsler vil overstige 18 kun $1 \%$ av dagene. I en stor
Tabell 2 Forventet prosentvis antall flere fødsler på ukedagene relativt til søndager. Inklusjon av ukedag som variabel ga signifikant bedre tilpasning (goodness-of-fit) ( $p<0,001$ ) enn grunnmodellen med kun år og måned (se også tab 1)

\begin{tabular}{lcc} 
Ukedag & Regresjonskoeffisient & Relativt til søndag (\%) \\
Mandag $^{1}$ & 0,0568 & 5,8 \\
Tirsdag $^{1}$ & 0,0725 & 7,5 \\
Onsdag $^{2}$ & 0,0336 & 3,4 \\
Torsdag $^{3}$ & 0,0525 & 5,4 \\
Fredag & 0,684 & 7,1 \\
Lørdag & 0,3525 & 3,6 \\
Søndag & Ref. & 0,0 \\
\hline
\end{tabular}

$1(p<0,001)$
$2(p<0,05)$
${ }^{3}(p<0,01)$

avdeling med 18 forventede daglige fødsler, vil dette tallet være 29 . De to mindre avdelingene vil med andre ord måtte planlegge for en kapasitet på til sammen 33 fødsler, fire mer enn den større. For en generell diskusjon av fordeler ved større enheter med tanke på forutsigbarhet av ankomster når disse er en Poisson-prosess, se Kirkwood \& Sterne (11, s. 234). En annen mulighet kan være å legge noen flere elektive fødsler til onsdager og torsdager eller å åpne for elektive «helgesnitt».

At fødselsrater varierer med sesongene er velkjent og godt forstått. Våre funn viser, som Aarnes \& Andersen (10), at septembertoppen beskrevet av Ødegård (1) er flyttet til tidligere på året. En mulig forklaring er at denne forskyvningen skyldes barnehageopptaket som fordrer fødsel før 1. september.

Funnet av en sterk og signifikant ukedagsvariasjon for spontane fødsler bekrefter det noe uventede funnet av ukedagsvariasjon i den danske studien (9). Hvorfor ser det ut til at også de ikke-elektive fødslene blir «gjort unna» på fredager og/eller utsatt til mandag eller tirsdag? En mulig forklaring er at gravide kvinner har ulik livsførsel i helgene og hverdagene, med ulik påvirkning på fødselsstart. Andre mulige forklaringer kan være at fødselsomsorgen i praksis kan være litt ulik i helgene og på hverdagene, eller at fødende oftere henvises til andre sykehus i helgene enn på hverdager.

Utover å gi støtte til hypotesen om Poisson-fordelte fødsler, bør ikke analysene av fødselsdataene fra Akershus universitetssykehus overfortolkes. Vi har kun analysert antall ikke-elektive fødsler, og det er ikke kontrollert for andre variabler.

Oppsummert fant vi at fødsler er (tids- trendjustert) Poisson-fordelte, med variasjon mellom måned og ukedag, og at datotallet ikke har noen forklaringskraft.

\section{Mathias Barra (f. 1977)}

er ph.d. i matematisk logikk og forsker. Han arbeider med matematisk modellering av pasientforløp, helseøkonomi, statistikk og livskvalitetsforskning.

Forfatter har fylt ut ICMJE-skjemaet og oppgir ingen interessekonflikter.

\section{Jonas C. Lindstrøm (f. 1988)}

er MSc i bioinformatikk og anvendt statistikk

Forfatter har fylt ut ICMJE-skjemaet og oppgir ingen interessekonflikter.

\section{Samantha S. Adams (f. 1981)}

er ph.d., lege og fastlegevikar ved Frysja legekontor.

Forfatter har fylt ut ICMJE-skjemaet og oppgir ingen interessekonflikter.

\section{Liv A. Augestad (f. 1980)}

er ph.d., lege og postdoktor.

Forfatter har fylt ut ICMJE-skjemaet og oppgir ingen interessekonflikter.

\section{Litteratur} tion and in patients with mental disorder in Norway. Br J Psychiatry 1974; 125: 397-405

2. MacFarlane A. Variations in number of births and perinatal mortality by day of week in England and Wales. BMJ 1978; 2: 1670-3

3. Mathers CD. Births and perinatal deaths in Australia: variations by day of week. J Epidemiol Community Health 1983; 37: 57-62. og er statistiker og forsker.

1. Odegård 0 . Season of birth in the general popula- 
4. Brunborg H. Få fødsler, mange unnfangelser. www.ssb.no/befolkning/artikler-og-publikasjoner/ fa-fodsler-mange-unnfangelser (5.10.2015)

5. Goodman MJ, Nelson WW, Maciosek MV. Births by day of week: a historical perspective. J Midwifery Womens Health 2005; 50: 39-43.

6. Lerchl A. Where are the Sunday babies? Observations on a marked decline in weekend births in Germany. Naturwissenschaften 2005; 92: 592-4.

7. Lerchl A, Reinhard SC. Where are the Sunday babies? II. Declining weekend birth rates in Switzerland. Naturwissenschaften 2008; 95: 161-4.

8. Lerchl A. Where are the Sunday babies? III. Caesarean sections, decreased weekend births, and midwife involvement in Germany. Naturwissenschaften 2008; 95: 165-70.

9. Gam CMB, Tanniou J, Keiding N et al. A model for the distribution of daily number of births in obstetric clinics based on a descriptive retrospective study. BMJ Open 2013; 3: e002920.

10. Aarnes H. Andersen T. Barnefødsler 1967-2012 analysert i R. Tidsskr Nor Legeforen 2014; 134 : 2245-6.

11. Kirkwood BR, Sterne JAC. Essential medical statistics. 2. utg. Malden, MA: Blackwell Science, 2003: 501.

12. Dønvold T. Sesongjusterte fødselsdata er ikke uniformt fordelt. Tilfeldig Gang 2014; nr. 2: 5. https://sites.google.com/site/statistiskforening/ tilfeldig-gang (23.10.2015).

13. Dønvold T. Sesongjusterte fødsler er ikke jevnt fordelt på datoer. Tidsskr Nor Legeforen 2014; 134: 1834

14. Wikipedia. Benford's law.

https://en.wikipedia.org/w/index.php?title= Benford\%27s_law\&oldid=682325873 (5.10.2015)

15. Medisinsk fødselsregister http://mfr-nesstar.uib.no/mfr/ (10.5.2015)

16. The R Foundation. The R project for statistical computing. www.R-project.org/ (5.10.2015).

17. Joenssen DW. BenfordTests: Statistical tests for evaluating conformity to Benford's law. http://CRAN.R-project.org/package=BenfordTests (10.5.2015).

18. Akaike H. Information theory and an extension of the maximum likelyhood pinciple. I: Selected Papers of Hirotugu Akaike. Berlin: Springer Science \& Business Media, 1998: 199-213.

19. Colin Cameron A, Windmeijer FAG. An R-squared measure of goodness of fit for some common nonlinear regression models. J Econom 1997; 77: $329-42$.

Mottatt 28.11. 2014, første revisjon innsendt 18.6. 2015, godkjent 23.10. 2015. Redaktør: Hanne Støre Valeur. 